\title{
Clinical Research in Hematology-Oncology in India during the COVID-19 Era
}

Parikh et al. recently reported a survey of challenges in the conduct of clinical trials during the COVID-19 pandemic faced by oncologists in India. ${ }^{[1]}$ There are a few national guideline on managing hemato-oncological disorders in the COVID-19 era, ${ }^{[2,3]}$ but none on managing the impact of COVID-19 on clinical research in hemato-oncological disorders. Our search on the Clinical Trials Registry of India on June 15, 2020, revealed that there were 46 interventional and 26 observational studies active for hemato-oncological disorders in non-COVID-19 patients. Compared to the high-income countries, the resources allocated toward laboratory and clinical research are limited outside of industry-sponsored trials. There has been a recent Indian Council of Medical Research (ICMR) guideline for the ethical committees overseeing clinical research during the COVID-19 pandemic. However, it is meant to guide ethics committees (ECs) and does not address the investigator- and industry-specific logistic issues in conducting clinical trials that have arisen because of the pandemic. The onus of conducting trials safely without compromising the integrity is primarily on the principal investigator and the research team. This is in contrast to several other national guidelines that are periodically updated to guide clinical trials in their jurisdictions. ${ }^{[4]}$ This evolved from identifying the challenges and changes suggested by surveys conducted by national societies. ${ }^{[8]}$ While all these guidelines are quite detailed, we highlight India-specific solutions that could be adapted to our setup.

1. The priority will always be the safety of trial participants. This is even more important for trials involving immunosuppressants, which is often the case for hematological disorders

2. The decision to halt or continue ongoing trial: This should be based on the risk:benefit assessment of the investigational medicinal product (IMP). For this purpose, the IMP can be categorized into three risk types (modified from the ICMR and Medicines and Healthcare Products Regulatory Agency): ${ }^{[9,10]}$

- Type A: Mild risk: Licensed drugs and doses, if off-label use in oncology, must be supported by published evidence or guidelines

- Type B: Minor risk: Already-licensed drug but for a new indication, modified doses, or novel combinations

- Type C: High risk: Involving unlicensed drugs.

The EC and the data and safety monitoring board (DSMB), if existing, can be involved with the investigators in making this decision.

3. For trials that are continued, measures to mitigate risks include minimizing the number of site visits, timed appointments, telemedicine visits, and 24-h helplines. Remote monitoring by involving local physicians should ensure confidentiality and may require additional consent. Electronic media portal must use end-to-end encryption to protect patient privacy and may require prior approval from EC

4. The risk to the health-care staff and the strain on compromised hospital resources also need to be considered. Care should be taken to ensure that monitoring activities are minimized to essential information only (e.g., primary end point data and safety reporting) until normal capacity resumes

5. To further limit the number of hospital visits, modifications to the trial protocol can be considered with communication to the EC. Ancillary investigations that are not essential to the stated objectives may be left out. Routine investigations can be outsourced to local accredited laboratories

6. Delivery of trial drug to participants: For self-administered drugs, courier services to mail trial drugs to the consenting patients can be considered with special mention of storage conditions

7. Timely reporting of serious adverse events (SAEs) from investigators to sponsors and of suspected unexpected serious adverse reactions from sponsors to the competent authority is paramount in protecting the safety of participants. It is possible that a trial patient may be diagnosed with COVID-19 and may experience $\mathrm{SAE}$ due to the disease/drug. The determination of causality of such SAEs to drug/COVID-19 should be left to the DSMB, which should independently compare the SAEs between COVID-19 patients on the trial drug and individuals in the control arm in a randomized controlled trial. The annual safety report should mention the deficiencies in reporting that may have arisen due to the pandemic

8. With the improvisations being introduced to the trial design and the inferior follow-up and reporting, "missing data" is inevitable. Missing values can have a significant impact on the analysis and results of the study. This needs to be addressed in collaboration with statisticians, and certain statistical tools can be employed to minimize their impact

9. For trials that have to be halted or restarted, it is critical that the regulatory agencies and the EC are informed. The interim analysis may be conducted if the data are deemed adequate

10. Contingency measures for trial patients who contract COVID-19 should be in place. A clear plan for their testing, transfer, and admission has to be formulated 
beforehand. All patients on immunosuppressive trial drugs should be tested before the start of therapy

A global survey that looked at the impact of COVID-19 on cancer research found that only $20 \%$ and $14 \%$ of institutions are continuing enrollment in the USA and Europe, respectively, ${ }^{[11]}$ while COVID-19 research is an urgent national priority, but this should not be at the cost of halted non-COVID-19 research that may include potentially life-preserving or life-extending treatments. ${ }^{[9,12]}$ The ICMR and the Central Drugs Standard Control Organization have detailed guidance documents for the ethical and practical conduct of clinical trials in the non-COVID-19 era. ${ }^{[13-15]}$ It is of the essence that similar guidance is provided in the COVID-19 era to ease the conduct of pragmatic non-COVID-19 research as well.

Financial support and sponsorship

Nil.

\section{Conflicts of interest}

There are no conflicts of interest.

\section{Nishant Jindal' ${ }^{1}$, Pankaj Malhotra1, Amol N Patil' ${ }^{2}$, Deepesh P Lad ${ }^{1}$}

${ }^{1}$ Department of Internal Medicine, Postgraduate Institute of Medical Education and Research, Chandigarh, India, ${ }^{2}$ Department of Clinical Pharmacology, Postgraduate Institute of Medical Education and Research, Chandigarh, India

Address for correspondence: Dr. Deepesh P Lad, Department of Internal Medicine, Postgraduate Institute of Medical Education and Research, Chandigarh - 160 012, India.

E-mail:deepesh.lad12@gmail.com

Submitted: 05 -Aug- 2020

Revised: 15 -Sep-2020

Accepted: 10-Dec-2020

Published: $31-$ Dec-2020

\section{References}

1. Parikh P, Mehta P, Krishna Kumar MV, Govind Babu K. Clinical trials facing "serious adverse events" during the ongoing COVID-19 pandemic. Indian J Med Paediatr Oncol 2020;41:2958 .

2. Jain A, Singh C, Dhawan R, Jindal N, Mohindra R, Lad D, et al. How to use a prioritised approach for treating hematological disorders during the COVID-19 pandemic in India? Indian $\mathrm{J}$ Hematol Blood Transfus 2020;36:605-15.

3. Indian Society for Blood and Marrow Transplantation (ISBMT). HSCT Guidelines for Transplant Practices during COVID-19 Pandemic in India. Blood Cell Therapy 2020;3:59-70.

4. Available from: https://www.fda.gov/emergency-preparednessand-response/mcm-issues/covid-19-related-guidance-documentsindustry-fda-staff-and-other-stakeholders. [Last accessed on 2020 Aug 01].
5. Available from: https://www.hma.eu/fileadmin/dateien/ Human_Medicines/01-About_HMA/Working_Groups/ CTFG/2020_03_CTFG_Link_to_National_guidance_on_CT managmant_during_the_COVID-19_pandemia.pdf. $-\overline{\text { Last }}$ accessed 2020 Aug 01].

6. Available from: https://www1.health.gov.au/internet/main/ publishing.nsf/Content/Clinical-Trials. [Last accessed on 2020 Aug 01].

7. Available from: https://www.gov.uk/guidance/managingclinical-trials-during-coronavirus-covid-19. [Last accessed 2020 Aug 01].

8. Waterhouse DM, Harvey RD, Hurley P, Levit LA, Kim ES, Klepin HD, et al. Early impact of COVID-19 on the conduct of oncology clinical trials and long-term opportunities for transformation: findings from an American Society of Clinical Oncology Survey. JCO Oncol Pract 2020;16:417-421.

9. Available from: https://ethics.ncdirindia.org//asset/pdf/EC Guidance_COVID19.pdf. [Last accessed on 2020 Aug 01].

10. Available from: https://assets.publishing.service.gov.uk/ government/uploads/system/uploads/attachment_data/file/343677/ Riskadapted_approaches_to_the_management_of_clinical_trials of_investigational_medicinal_products.pdf. [Last accessed 2020 Aug 01].

11. Upadhaya S, Yu JX, Oliva C, Hooton M, Hodge J, HubbardLucey VM. Impact of COVID-19 on oncology clinical trials. Nat Rev Drug Discov 2020;19:376-7.

12. Available om: https://www.nihr.ac.uk/documents/restartframework/24886. [Last accessed on 2020 Aug 01].

13. Available from: http://www.bspublications.net/9789352301669/ pdf $\% 20$ files/CDSCO-handbook $\% 20$ for $\% 20$ applicants $\% 20 \& \% 20$ reviewers $\% 200 \mathrm{o} \% 20$ Clinical $\% 20$ Trials.pdf. [Last accessed on 2020 Aug 01].

14. Available from: https://ethics.ncdirindia.org/ICMR_Ethical_ Guidelines.aspx. [Last accessed 2020 Aug 01].

15. Available from: https://cdsco.gov.in/opencms/opencms/system/ modules/CDSCO.WEB/elements/download_file_division. jsp?num_id=NDI2MQ. [Last acessed 2020 Aug 01].

This is an open access journal, and articles are distributed under the terms of the Creative Commons Attribution-NonCommercial-ShareAlike 4.0 License, which allows others to remix, tweak, and build upon the work non-commercially, as long as appropriate credit is given and the new creations are licensed under the identical terms.

Access this article online

\begin{tabular}{|l|l|}
\hline \multicolumn{2}{|c|}{ Access this article online } \\
\hline Quick Response Code: & Website: \\
& www.ijmpo.org \\
\cline { 2 - 2 } & DOI: \\
\hline
\end{tabular}

How to cite this article: Jindal N, Malhotra P, Patil AN, Lad DP. Clinical research in hematology-oncology in India during the COVID-19 era. Indian J Med Paediatr Oncol 2020;41:799-800. 